variation, chi-square and t-test with varying degrees of clarity. The introduction at an early stage of the equation to the normal curve contributes little to understanding and will dishearten the amateur doggedly working his way through the formulae.

Page 176 bears witness to careless proof reading, for it carries three minor errors and a major one in the formulation of the basic expression of the value of Student's t.

The worked examples in the text are admirably chosen, many from recent medical publications. Why, though, are there no answers or working check for the problems set at the end of each chapter?

H.K.

\section{NEW AND NONOFFICIAL DRUGS, 1958}

Evaluated by the Council on Drugs of the American Medical Association. Pp. $x x x+645$. London: Pitman Medical Publishing Co. Ltd. 1958. $30 \mathrm{~s}$.

The aim of this annual publication is to be as up to date as is possible, and there is no doubt that the aim has been achieved. There are about 48 new additions to the list of drugs, including mecamylamine hydrochloride, novobiocin, cycloserine, promazine hydrochloride and tolbutamide. In fact, there are few drugs of recent origin which are not mentioned, proguanil, bemegride and amiphenazole being amongst the more useful of those omitted.

As would be expected in a work written by experts in their own field and carefully edited into an integrated whole, the accounts of the drugs are concise, factual and accurate. The amount of space devoted to any one drug varies from a few words to about four pages. A drug is listed wherever possible under its U.S.P. name (a slight disadvantage to British readers) or else its generally accepted name, e.g. primidone, and formula, actions and uses (including toxicity) and dosage are given. The general arrangement is in chapters, each of which is devoted to some class of drugs, e.g. autonomic drugs, central nervous system depressants. Information is given on vaccines, isotopes and the use of drugs in diagnosis.

One might quarrel with certain aspects in the balance of the work. Is information on biotin, chlorine and the hypochlorites really necessary, one wonders, in a book of such modernity? The index does not include clinical conditions, which fact somewhat detracts from its use as a reference book, though the list of contents at the beginning is very informative. The sections on antibiotics, hormones and hormone substitutes are excellent. There is, strangely enough, almost no data on tranquillizing agents.

The general practitioner, and also the medical consultant, may well find a place for this handy book (it is only $7 \frac{1}{2}$ by 5 in.) in their library as a quick reference book. The lack of bibliography rather precludes use of the book by those engaged in teaching therapeutics; the omission of old and tried compounds, such as magnesium trisilicate and various older purgatives, and also the transatlantic fashion in anti-histamine drugs (which so differs from our own fashion) makes one hesitate in recommending the book to students unless in conjunction with a standard work on therapeutics.

W.H.H.A.

\section{BRITISH MEDICAL BULLETIN \\ Volume 14, Number 2}

Edited by E. Boyland, D.Sc., Ph.D. Pp. 73-196, with four plates. London: British Council. 1958. $25 \mathrm{~s}$.

This number of the British Medical Bulletin comprises of an introduction by Professor A. Haddow and 21 review articles representing the main contributions to work on carcinogenesis made by British investigators during the last decade. More than half the articles are chiefly concerned with chemical carcinogenesis, and this is a fitting tribute to and reflection of the classic contributions made by the late Sir Ernest Kennaway. The frontispiece is an excellent portrait of this great man. Five articles are devoted to radiation carcinogenesis, one to immunological theories and one avian carcinogenesis. The very important recent contributions made in the fields of virus carcinogenesis and tissue culture are almost entirely neglected. The articles are clearly presented, excellently illustrated, and cover their specific fields well. The lists of reference are particularly useful.

E.A.W.

\section{LUMBAR DISC LESIONS}

By J. R. Armstrong, M.D., M.Ch., F.R.C.S. Second edition. Pp. xii +244 , with 60 illustrations. Edinburgh: E. \& S. Livingstone Ltd. I $958.45 \mathrm{~s}$.

The second edition of Mr. Armstrong's monograph makes a welcome appearance. A number of chapters have been enlarged by the inclusion of recent work on various aspects of the subject.

The chapters on the functions of intervertebral discs include summaries of recent papers on the range of movements in the lumbar spine.

The section on aetiology includes recent theories, involving factors other than trauma, including disordered fluid balance and mental stress.

The use of myelography is discussed in the chapter on investigations. The author reflects current practice in reserving this investigation for the elucidation of obscure spinal conditions, such as tumours. He feels it plays no part in the routine investigation of the level of a disc protrusion.

The chapters on conservative management of lumbar disc lesions are concerned with the treat- 
ment of the majority of cases. The author stresses the importance of complete bed rest in acute cases. $\mathrm{He}$ discusses the use of plaster jackets and lumbar corsets in the management of patients whose acute symptoms have subsided.

The more popular therapeutic measures at present in vogue in physical medicine departments are considered in some detail, including manipulation, the use of traction tables, and extra-dural injections. In general, the author condemns these measures because of their unpredictable effects and their probable hazards.

In the section on operative treatment, the controversial topic of the best exposure for dealing with disc lesions is discussed. The author amply justifies his preference for the hemilaminectomy exposure rather than the interlaminar approach. He stresses the importance of exposing and examining both lower disc spaces, even where a large protrusion has already been found at the first level. Double lesions are estimated to occur in between ro per cent. and 20 per cent. of cases.

This book gives a comprehensive survey of the subject in a lucid and readable fashion. The management of cases as practised by the author is described in detail and is, of necessity, dogmatic in places. The X-ray reproductions are of good quality and the illustrations, are clear and wefl labelled, though figures $3 \mathrm{I} B$ and $C$ seem to $b B$ transposed. This is a book which can be read with pleasure and profit by all who are interested in the problem of low back pain and sciatica.

SURGERY FOR STUDENTS OF NURSING By John CaIRNeY, D.Sc., M.D., F.R.A.C.S్ Pp. 359. Christchurch, New Zealand: N. M. Peryer Ltd. 1958. 40s.

The third edition of this textbook by the Directo General of Health, for the Dominion of New Zealand, reads like a series of lectures given ween by week to a class of student nurses. It deals wit $\underline{\underline{B}}$. each subject simply and clearly, and the text is helped by the line diagrams. There is a new chapter on anaesthesia, which is slight but currente Much of the true nursing care is a mere synopsis of the necessary treatment, but the practical nurser would be stimulated to add details from her ow observations, and to read further, as each subject is introduced in so interesting a manner.

W.E.F., S.R.N., O.N.C., S.T.D.

\section{Manufacturers' Notes}

Boots Pure Drug Co. Ltd. announce the introduction of Deltastab Injection: a sterile suspension of Prednisolone Acetate, B.P., $25 \mathrm{mg}$. per ml., supplied in rubber-capped vials each containing $5 \mathrm{ml}$. It is designed for injecting into joints affected by various forms of arthritis (rheumatoid arthritis, osteo-arthritis, etc.) and for injecting into the soft tissues surrounding joints in such conditions as tennis-elbow, etc. The methods of administration are the same as for intra-articular hydrocortisone, but Deltastab Injection is effective in half the dosage. This is particularly advantageous when treating small joints such as those in fingers or toes. The basic N.H.S. price of Deltastab Injection is 30s. per vial.

\section{VANDID}

Vandid, vanillic acid diethylamide: follow ing the increasing employment of Vandid in the termination of and or lightening of thiopentone anaesthesia, the manufacturers, Carnegies of Welwyn, have received interesting reports show ing the usefulness of Vandid in this field. Adopting the suggestions given in these reports that atten $N$ tion should be called to the potency of Vandidis an addition is being made to the current Vandif. literature, under the heading 'Indications and Dosage,' which reads as follows:

' For reversing the effects of thiopentone anaesthesia I-2 ml. intravenously of 5 per cent.0 injection solution.' 